\title{
FRONTEIRA, CONFLITOS E ESTADO DE EXCEÇÃO
}

\author{
Marcos Mondardo \\ UFGD - Universidade Federal da Grande Dourados
}

\section{Resumo}

No estado do Mato Grosso do Sul, na faixa de fronteira do Brasil com o Paraguai, em relação à condição humana dos povos indígenas, existe um Estado de exceção declarado. Muitos direitos consuetudinárioconstitucionais são negados, como os direitos territoriais e humanos. Devido aos processos de demarcação e ao movimento de autodemarcação das terras indígenas, esses grupos étnicos vivenciam a condição de insegurança social ao se tornarem alvos de violência, de assassinatos, suicídios e genocídios. Se os conflitos e confrontos colocam em xeque ainda mais a "vida nua" e a condição de exceção desses povos, as ações de retomadas de tekoha são a possibilidade concreta do devir indígena no estado.

Palavras-chave: Fronteira; Insegurança; Território; Guarani; Kaiowá.

\section{Resumen}

En el estado de Mato Grosso do Sul, en la franja de frontera de Brasil con Paraguay, en relación con la condición humana de los pueblos indígenas, existe un Estado de excepción declarado. Muchos derechos consuetudinario-constitucionales son negados, como los derechos territoriales y humanos. Debido a los procesos de demarcación y al movimiento de autodemarcación de las tierras indígenas, esos grupos étnicos experimentan la condición de inseguridad social al convertirse en blancos de violencia, de asesinatos, suicidios y genocidios. Si los conflictos y enfrentamientos ponen en jaque aún más la "vida desnuda" y la condición de excepción de esos pueblos, las acciones de retomadas de tekoha son la posibilidad concreta del devenir indígena en el estado.

Palabras clave: Frontera; Inseguridad; Territorio; Guarani; Kaiowá.

\section{Introdução}

Nós Guarani Kaiowá não temos segurança. A polícia militar e a civil vêm na área de retomada, mas não para dar segurança para a gente, mas para tirar a gente. (...) Quando o índio morre ninguém vai para a cadeia. Quando o índio morre ninguém vai preso. A morte indígena não vale nada?

(Kaiowá do Tekoha Guyra Kambi'y, Douradina/MS, entrevista realizada em 27/06/2018).

\footnotetext{
A luta pela terra, território e direitos humanos dos povos indígenas no estado de Mato Grosso do Sul, na faixa de fronteira do Brasil com o Paraguai, tornou esse espaço um verdadeiro laboratório de conflitos e confrontos territoriais, que geram insegurança social pela precariedade vivida pelos grupos étnicos. No depoimento de abertura deste texto, o Kaiowá questio-
} 
na a negligência do Estado com as violências sofridas, pois "quando o índio morre ninguém vai preso. A morte indígena não vale nada?". A vice-Procuradora Geral da República, Deborah Duprat, afirmou, em entrevista concedida durante sua participação em evento do Ministério Público Federal na cidade Campo Grande, Mato Grosso do Sul, no ano de 2010, que o drama humano vivido pelos indígenas no estado está vinculado diretamente à "insuficiência de terras". Essa restrição territorial coloca os Guarani e Kaiowá em condição de "vida indigna", ou como analisaremos, numa acepção agambeniana, de "vida nua", em tempos de Estado de exceção. De forma emblemática, Duprat afirma que "a reserva de Dourados é talvez a maior tragédia conhecida na questão indígena em todo o mundo. (...) é a coisa mais indigna que existe” (DUPRAT, 2011, p. 24). E acrescenta, "em MS, geralmente a questão indígena é tratada como uma questão policial ou então resolvida à bala. Dos diversos assassinatos de indígenas, até hoje ninguém foi julgado e condenado" (DUPRAT, 2011, p. 27). O depoimento do Kaiowá e a declaração da vice-Procuradora Geral da República evidenciam a situação dramática do espaço cotidiano marcado pela insegurança social e pelo racismo de Estado para os povos indígenas.

O objetivo deste trabalho é, assim, problematizar a multiplicidade de conflitos territoriais no movimento antisistêmico ${ }^{1}$ de resistência dos Guarani e Kaiowá na luta pelo retorno aos territórios tradicionalmente ocupados, os tekoha. Buscamos entender as dinâmicas territoriais relativas aos conflitos em torno da demarcação das terras indígenas associadas às condições de sobrevivência físico-biológica e cosmológica destes povos. A noção de conflitualidade que utilizamos é bastante ampla, desde aquela efetivamente ligada à luta pela terra, de confrontos e enfrentamentos em acampamentos de retomadas de territórios tradicionais localizados às margens de rodovias ou em áreas reocupadas em fazendas, ao bloqueio de fluxos e/ou fechamentos temporários de vias de circulação, às táticas de fortalecimento e valorização identitária por meio dos direitos humanos como saúde, educação, alimentação e moradia, até a luta pela própria "r-existência" biológica, tendo em vista os alarmantes índices de assassinatos de indígenas registrados no Brasil e principalmente no Mato Grosso do Sul como se verá mais adiante. Para isso, analisaremos ações e práticas de luta e resistência em meio à "in-segurança", exceção e "des-controle" socioterritoriais vividos na faixa (que, por vezes, extrapolam e/ou se projetam sobre a zona) de fronteira do Brasil com o Paraguai.

Esta pesquisa é um desdobramento de outros trabalhos (MONDARDO, 2009; 2012; 2013; 2014; 2017; 2018a; 2018b), no âmbito da Geografia Regional contemporânea (CRESSWELL, 2013), revisitando o conceito de território na Geografia (HAESBAERT; 2001; 2014; 2016), e nas demais Ciências Sociais (RIBEIRO; MILANI, 2009), para fazer o encontro com os conceitos nativos, como sugere Souza (2013), de tekoha e das ações de retomadas (acampamentos indígenas).

\footnotetext{
${ }^{1}$ Para Wallerstein (2005) os movimentos sociais assumem uma perspectiva antisistêmica pela necessidade de lutar contra o capital e o regime neoliberal. Segundo Wieviorka (2006), o movimento social compreende um princípio de conflitualidade que estrutura a vida coletiva. Nessa perspectiva, ao longo das décadas de 1970 e 1980 entrou em cena outro modelo de movimento social, os Novos Movimentos Sociais, como concebe Touraine (2006). Esses Novos Movimentos Sociais são caracterizados por uma forte carga cultural, com ênfase às identidades/territorialidades e às ações coletivas. Fraser (2006) identifica no começo do século XXI a problemática política das ações coletivas em dois eixos conflitantes e complementares: por um lado, a luta por reconhecimento das diferenças de grupos mobilizados em torno de questões de etnia, raça, nacionalidade, gênero, dentre outros; por outro lado, a tradicional luta por redistribuição econômica que consiste em combater a desigualdade social aviltante de renda, na posse e uso de recursos naturais (como a terra e água), propriedades e direitos humanos.
} 
A metodologia da pesquisa foi delineada pelo método qualitativo e quantitativo. A utilização da abordagem multimetodológica, ou método misto, visa, de acordo com Flick (1992), expandir as perspectivas metodológicas para que as pesquisas não se alicercem somente na premissa de métodos específicos. Na tentativa de se aproximar da realidade em questão, isto é, da complexidade do fenômeno, optamos pela abordagem multimetodológica que pressupõe a combinação de métodos mistos. Nesta pesquisa, além da escolha de conceitos nativos - que se tornaram, hoje, "armas de luta" para os Guarani e Kaiowá - como o de tekoha, as técnicas empregadas variaram de acordo com a natureza do fenômeno observado, bem como, com a familiaridade e habilidade em campo. Utilizamos o levantamento bibliográfico, documental, coleta de dados e informações, observação (que variou de observador à participante), descrição, entrevistas e atividades em campo.

Os resultados e discussões deste texto se estruturam a partir de duas categorias criadas: 1) Conflitos territoriais em áreas de fronteira, em que analisamos a atuação do Estado na criação de reservas e as violências sofridas pelos povos indígenas, com destaque para os alarmantes índices de assassinatos dos Guarani e Kaiowá no Mato Grosso do Sul; e, 2) Retomadas de territórios tradicionais, na qual destrinchamos as retomadas de territórios tradicionais, e nela identificamos como a relação dos Kaiowá com a morte e a terra em meio à violência extrema reelabora as territorialidades em conectividade com o direito ao tekoha. Analisamos também como os Guarani Ñandeva produzem uma territorialidade (trans)fronteiriça de resistência no trânsito entre Brasil e Paraguai.

\section{Conflitos territoriais em áreas de fronteira}

Como analisamos em Mondardo (2018a, p. 127), a ocupação colonial da fronteira do Brasil com o Paraguai ocorreu por uma densa dinâmica espaçotemporal ao longo do século XX e neste início de XXI, marcada por sucessivas e sobrepostas frentes de colonização. "Desde a criação de reservas indígenas, passando pela expansão territorial das chamadas frentes de ocupação e colonização até a modernização da agricultura e a implantação do agronegócio, observamos a questão do domínio e do controle da terra" pelo não indígena. Entre os anos de 1915 a 1928, o Serviço de Proteção aos Índios (SPI) criou oito pequenas áreas - reservas indígenas multiétnicas - que desterritorializou/expulsou os povos Guarani, Kaiowá e Terena (dentre outros grupos étnicos) por "despossessão" (HARVEY, 2004), saque e/ou esbulho de seus tekoha².

A criação das reservas pela biopolítica colonial do Estado brasileiro foi um fenômeno basilar para a negação dos direitos territoriais indígenas e a tentativa de integração à sociedade nacional pela lógica de desterritorialização (destruição de seu teko-ha, o modo de vida e organização socioespacial) por meio da assimilação cultural. Na formação da sociedade moderna-colonial (MIGNOLO, 2003), as reservas indígenas foram criadas por uma geopolítica do conhecimento, a

\footnotetext{
2 Nesse período foram criadas respectivamente as reservas de Amambaí (1915), Dourados (1917), Caarapó (1924), Pirajuí (1928), Limão Verde (1928), Porto Lindo (1928), Sassoró (1928) e Takuaperi (1928).
} 
colonialidade do saber e do poder3 (QUIJANO, 2005), e funcionaram como um dispositivo de controle socioespacial que teve capacidade de capturar, orientar e modelar as territorialidades dos Guarani e Kaiowá para a inscrição territorial estatal, como na tríade concebida classicamente por Ratzel (2011) do solo, a sociedade e o Estado.

Por isso, é possível afirmar que no processo de territorialização da sociedade disciplinar nacional, as territorialidades que estavam fora da inscrição estatal "civilizatória" foram controladas pelo dispositivo do território-zona-reserva. A reserva foi um "dispositivo" (AGAMBEN, 2009) para o Estado produzir, não somente pelo exercício da violência, uma subjetividade própria inscrita no socius por uma série de práticas e discursos (DELEUZE, 2004). Foi imposta uma lógica de sujeição às territorialidades indígenas pela definição de novos limites socioterritoriais com a criação de "espaços mínimos" de sobrevivência. Nesse processo de expansão da sociedade nacional pelas frentes de colonização as terras indígenas foram saqueadas pelo Estado por meio da lógica de acumulação por espoliação.

Harvey (2004) cunhou o termo "acumulação por despossessão" (ou espoliação) para definir as práticas fundantes da busca por lucro no neoliberalismo, incluindo a financeirização, a manipulação de crises e a privatização. A princípio, a despossessão era a incorporação de áreas ainda não atingidas pelas relações capitalistas, especialmente no mundo colonial, como o saque/desterritorialização das terras indígenas para a pecuária e agricultura no Brasil. $\mathrm{Na}$ era da globalização, caracterizada pela mercantilização imposta pelo neoliberalismo, por um lado, regiões novas foram incorporadas ao mercado mundial, a exemplo daquelas funcionais do agronegócio brasileiro. Nesse processo de acumulação, para Harvey, identifica-se o uso de mecanismos extra-econômicos para realização da acumulação: o roubo, a fraude e a violência. Por isso, como afirma Harvey (2018, p. 171), no capitalismo neoliberal a "loucura da razão econômica" tornou a vida cotidiana "refém da loucura do dinheiro". O dinheiro tornou-se, assim, o centro do mundo.

Hoje, se muitos grupos de minorias sociais dependem da fronteira enquanto espaço estratégico para lutar e resistir (SANTOS, 2007), e/ou "viver no limite" entre o legal e o ilegal, a ordem e a desordem, o poder hegemônico e a resistência (HAESBAERT, 2014), por outro lado, esse espaço também é produzido no mundo pelas ações de contenção, violência, de desreterritorialização o desfazer e refazer constante de territórios e territorialidades (RAFFESTIN, 1993) -, em um regime de "Estado de insegurança" (LOREY, 2015) e/ou de "Estado de exceção" (AGAMBEN, 2004). Para Lorey (2015), o Estado de insegurança que vivemos tem como mote o governo das precariedades. Como constatamos, no caso das populações tradicionais, muitas vezes, a violência contra os povos indígenas tem partido de quem deveria protegê-las: o Estado.

A condição de "Estado de exceção" (AGAMBEN, 2004) em que vivem estas populações torna-se alarmante, pois o próprio Estado tornou-se difusor do terrorismo pelas ações de violência física, despejos, ameaças, intimidações e assassinatos. Não faltam ocorrências de conflitos e confrontos entre o poder público, de polícia (municipal, estadual e federal), articuladas por vezes com o poder privado, fazendeiros, multinacionais e até empresas particulares de "segurança", com ordens de despejo e/ou expulsões dos povos indígenas de áreas de retomadas bem como de seus territórios originários. Esse momento da globalização da economia no regime neoliberal se

\footnotetext{
${ }^{3} \mathrm{Na}$ fronteira do Brasil com o Paraguai a colonialidade do saber e do poder atua sobre os povos indígenas, Guarani e Kaiowá, de várias maneiras, seja ocultando-os da história, invisibilizando-os do espaço, estereotipando-os nos lugares e inferiorizando-os na relação com o moderno.
} 
caracteriza, como definiu Sassen (2015), pela brutalidade das expulsões das minorias étnicoraciais e nacionais de seus territórios.

Com relação a essa articulação entre poder público e poder privado, no Mato Grosso do Sul a vigilância territorial é integrada por sindicatos patronais, militares da reserva e da ativa, comerciantes, fazendeiros e empresas multinacionais, que vem profissionalizando a violência e terceirizando a gestão dos conflitos fundiários no estado. É possível afirmar que se configura com isso um "Estado de exceção permanente" (AGAMBEN, 2004) pela negação cotidiana de direitos consuetudinário-constitucionais dos povos tradicionais. Os Guarani e Kaiowá estão "presos" em seu próprio território, que hoje é controlado pelas modernas fazendas do agronegócio, articuladas com as empresas nacionais, estrangeiras e o Estado.

$\mathrm{Na}$ última década, o Mato Grosso do Sul liderou o ranking dos estados mais violentos contra os povos indígenas no Brasil. Os Relatórios de violências contra os povos indígenas no Brasil, publicados pelo Conselho Indigenista Missionário (CIMI), registraram números alarmantes sobre os assassinatos de indígenas no país. Para identificar essa realidade, realizamos a coleta de dados organizados pelo CIMI e apresentados em seus relatórios ao longo dos últimos 15 anos, e sistematizamos os números, com relação aos assassinatos, para retratar a situação dos povos indígenas no país. No período de 2003 a 2017, o CIMI registrou 863 casos de indígenas assassinatos em todo o Brasil. Em média, nos últimos 15 anos, 57 indígenas foram assassinados por ano em território nacional.

Destes 863 casos, 434 foram registrados no Mato Grosso do Sul, o que corresponde a $50,2 \%$ de todos os indígenas assassinados no Brasil no período analisado. A média de assassinatos de indígenas no estado sul-mato-grossense, nesse intervalo, é de quase 30 mortes ao ano $(28,9 \%)$. Tais números assustam ainda mais quando comparados com outros estados. Das 26 UFs e mais o Distrito Federal, quatro estados brasileiros não contabilizaram nenhum registro de assassinatos no período: Piauí, Rio de Janeiro, Rio Grande do Norte e Sergipe. Dos outros estados, o que ficou em segundo lugar no número de assassinatos de indígenas, atrás de Mato Grosso do Sul, é a Bahia, com 55 casos registrados, o que corresponde a 6,3\% do total nacional. Este número é quase oito vezes menor do que o do estado sul-mato-grossense. Destaque também para o Amazonas com 43 registros (4,9\%), Pernambuco com 32 casos (3,7\%) e Roraima com 30 ocorrências $(3,4 \%)$, respectivamente (figura 1$)$.

De acordo com um destes relatórios do CIMI, no ano de 2014 o Mato Grosso do Sul apresentou uma situação alarmante de violência contra indígenas. Foram 27 assassinatos, 12 tentativas de assassinatos, 9 homicídios culposos, 7 ameaças de morte, 6 casos de violência sexual, 5 lesões corporais dolosas e 3 ameaças de outra natureza, que totalizam 67 ocorrências no estado. 


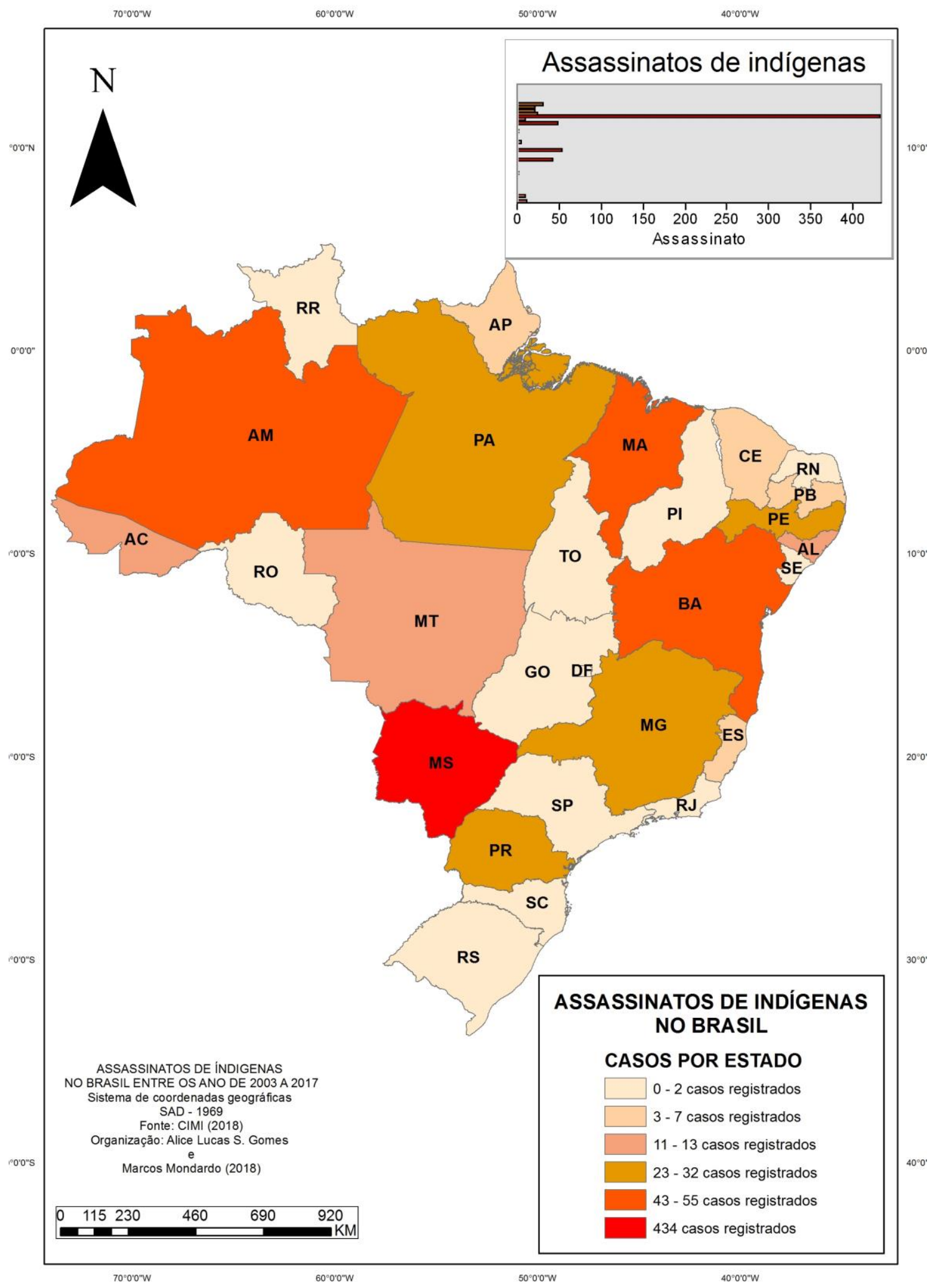

Figura 1. Assassinatos de indígenas no Brasil registrados pelo CIMI de 2003 a 2017 
Dados mais recentes demonstram a continuidade dos conflitos relativos aos direitos territoriais no Brasil, com destaque mais uma vez para o Mato Grosso do Sul. Segundo o CIMI (2016), foram registrados no ano de 2016, 12 ocorrências de conflitos relativos à luta por territórios tradicionais, contendo um caso nos estados do Amazonas, Mato Grosso, Pernambuco, Santa Catarina e Rio Grande do Sul, e sete no Mato Grosso do Sul. O relatório de 2016 destacou a situação dos Guarani e Kaiowá no estado sul-mato-grossense que continuou apresentando o maior número de ocorrências de violência contra indígenas no país. A média geral de homicídios no estado foi neste ano de $27,71 \%$ de pessoas a cada 100 mil habitantes, mas entre os povos indígenas foi de $43,26 \%$, e entre os Guarani e Kaiowá a média aumenta para os impressionantes $62,26 \%$.

Tomando por base os dados acumulados e detalhados que os Relatórios do CIMI apresentam, é possível fazer uma necrocartografia (figura 2) dos municípios em que ocorreram, e em quais mais apresentaram assassinatos de Guarani e Kaiowá no Mato Grosso do Sul. Dourados, o segundo maior município do estado em número populacional (220 mil habitantes em 2018, segundo o IBGE), e onde está localizada a reserva indígena mais populosa do Brasil (15.023 indígenas habitando uma área de 3.474 hectares), se destaca nos casos de homicídios de indígenas Guarani e Kaiowá. Dos 400 assassinatos registrados no estado pelos relatórios do CIMI, 164 ocorreram em Dourados. Este número é referente a $41 \%$ das mortes de Guarani e Kaiowá em todo o estado no período analisado (2003 a 2017). Estas mortes correspondem ainda a 37,7\% do total dos assassinatos de indígenas em Mato Grosso do Sul e 19\% em todo o Brasil. Os números apontam ainda que em média quase 11 indígenas são assassinados por ano no município de Dourados. O confinamento, a insuficiência de terras e a lógica compulsória/disciplinar imposta sobre as territorialidades Guarani e Kaiowá têm justificado, em parte, o maior número de assassinatos e conflitos na Reserva Jaguapirú e Bororó em Dourados.

Outro município que se destaca é Amambai. O mesmo registrou 95 assassinatos de Guarani e Kaiowá, o que corresponde a $23 \%$ de todas as mortes por assassinato da etnia no estado. Estas mortes em Amambai correspondem a 21,7\% das ocorridas em Mato Grosso do Sul e $11 \%$ das nacionais. Neste município, cerca de seis indígenas Guarani e Kaiowá são assassinados por ano em média. Destaque também para Caarapó, município vizinho de Dourados, onde 34 Guarani e Kaiowá foram assassinatos no período analisado, o que equivale a 8,5\% de todas as mortes da etnia no estado. Outros municípios que se destacam no número de assassinatos de Guarani e Kaiowá foram Japorã e Coronel Sapucaia com 15, Tacuru com 12 e Paranhos com 10.

Nessa lógica necropolítica (MBEMBE, 2011) de eliminação/extermínio do Outro pelos assassinatos, é importante lembrar que, nos fronts de batalha pela demarcação das terras, lideranças indígenas são marcadas para morrer. São exemplos trágicos de lideranças assassinadas devido aos conflitos territoriais: Genivaldo Verá, Rolindo Verá, Marco Veron, Shurite Lopes, Ortiz Lopes, Durvalino Rocha, Dorival Benites e Nísio Gomes

\footnotetext{
${ }^{4}$ A professora e liderança indígena Valdelice Veron (2011, p. 30) denuncia a situação de violência ao afirmar que "no Mato Grosso do Sul existe um povo, uma nação Guarani-Kaiowá que está lutando por um pedacinho de terra e que hoje está acontecendo um massacre, uma violência muito grande, muito forte lá, contra nosso povo. Não está sendo fácil para nós. Não está sendo fácil porque nós líderes indígenas estão sendo mortos. Em 2007, Mato Grosso Sul ficou em primeiro lugar na matança, no massacre dos líderes indígenas. E hoje estamos sendo perseguidos. Nós professores indígenas estamos sendo perseguidos. Estamos sendo perseguidos porque nós professores indígenas Guarani-Kaiowá estamos começando a escrever a nossa história, da nossa forma, do jeito que a gente sabe a nossa história verdadeira.
} 


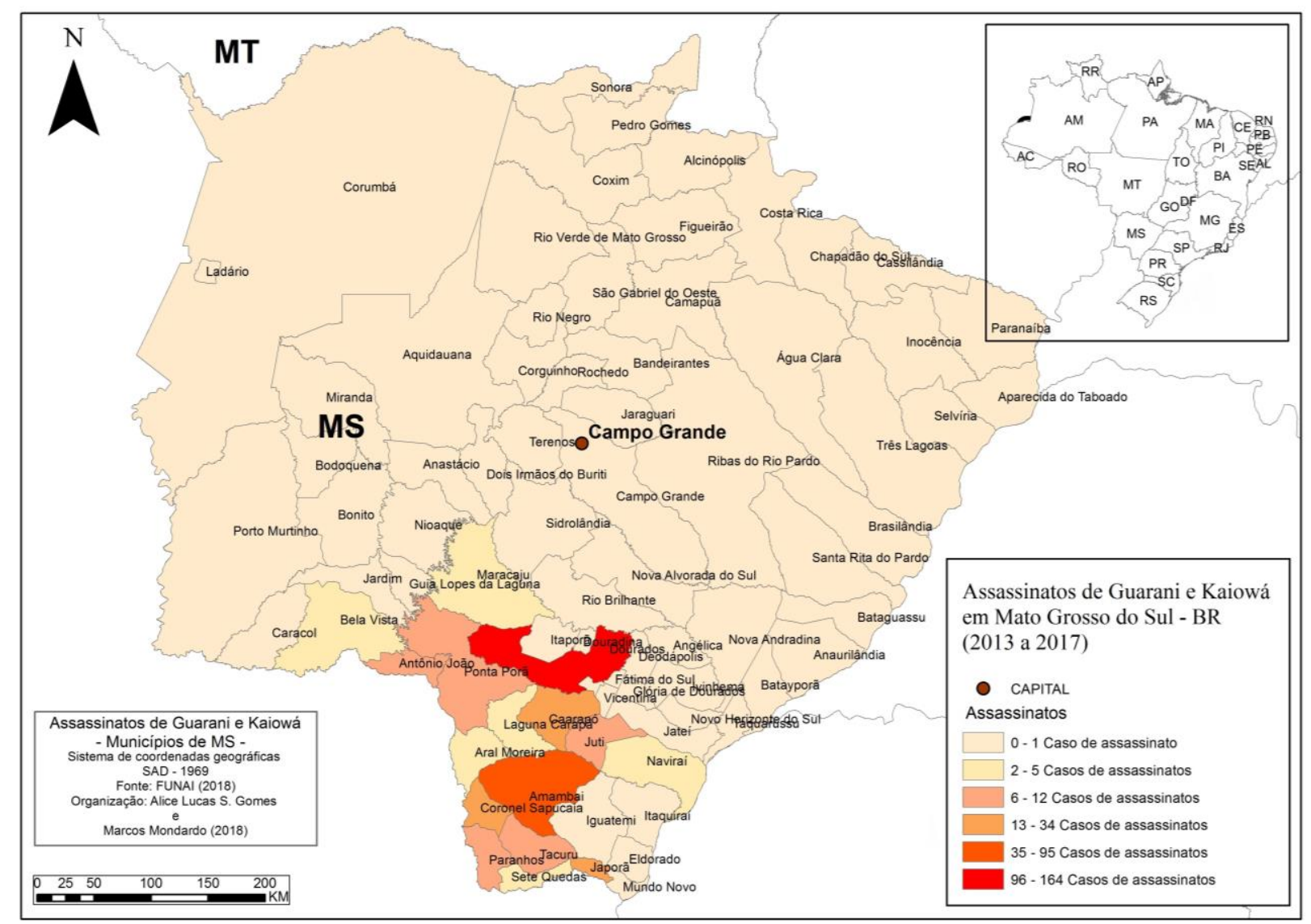

Figura 2. Assassinatos de Guarani e Kaiowá por município em Mato Grosso do Sul, com base em dados coletados pelo CIMI de 2003 a 2017.

No Mato Grosso do Sul os conflitos entre indígenas e fazendeiros passam por essa condição de Estado de exceção permanente vivida pelos povos Guarani e Kaiowá que, mesmo em condições precárias e de insegurança, resistem em acampamentos às margens das rodovias em barracos de lona na luta pelo retorno aos tekoha. A "fronteira", por meio da territorialização desses "espaços de exceção", é construída num limbo jurídico-político pelas posições tomadas pelo Estado brasileiro na questão no que concernem as ações de despejo e outras formas de violência física e simbólica contra esses povos, além da morosidade e negligência nos processos que envolvem a demarcação das terras indígenas.

Na esfera econômica, Oliveira (2007), inspirado na proposição benjaminiana (mas sem fazer referência a Agamben), desdobra o conceito de Estado de exceção frente à realidade brasileira contemporânea. Para o sociólogo, na "era de indeterminação" em que vivemos, do "desmanche do Estado" promovido pela economia neoliberal no Brasil a partir da década de 1990, a exceção se tornou a regra da governabilidade. Nessa gestão de incertezas, as minorias ficam, quase sem-

Quando estamos começando a escrever a nossa história, estamos sendo mortos. Dois professores nossos foram jogados no rio. Um foi encontrado e o outro nós não encontramos o corpo. A Polícia Federal não está mais procurando o corpo. Nós não sabemos o que aconteceu. Esse professor tem quatro filhinhos e a gente não sabe o que vai falar para sua esposa, para sua família. Não temos o que falar. A gente não sabe para onde ir, a quem recorrer. Como é que vai ser? Vão continuar a busca ou não?". 
pre, na retórica das causas emergenciais em detrimento das vantagens no processo de acumulação do capital cada vez mais mundializado. O autor reconhece que o Estado de exceção é, hoje, a categoria analítica que denuncia a destruição da política num momento em que os atores e os pobres transitam na indeterminação da desenfreada acumulação capitalista no regime neoliberal.

A "era da indeterminação" é produzida pelos efeitos da financeirização do capitalismo, pela explosão da dívida externa dos países subdesenvolvidos e pela perda da centralidade do trabalho fixo, promovido pelos avanços técnicos, científicos e informacionais do período atual (SANTOS, 1997). A sociedade brasileira perdeu sua forma no desmanche realizado pela economia neoliberal nas últimas duas décadas. Essa destruição geradora de obscuridade e desfiguração, segundo Oliveira (2007), torna a exceção à forma da política contemporânea do capitalismo periférico ao traduzir-se praticamente em uma norma, uma regra geral instituída em nossa sociedade. Ela é a regra para os países em desenvolvimento como o Brasil. Essa categoria - Estado de exceção possibilita, assim, uma análise da teoria política para compreender a situação emblemática e específica na qual o exercício pleno da política não ocorre, mas, se institui como prerrogativa pela combinação sacrossanta entre administração cotidiana e coerção por meio, hoje, de um refortalecimento do monopólio da violência.

Esse estado permanente de executar tarefas emergenciais - ad hoc - só se inscreve no Estado quando a exceção se tornou a norma, a regra universal. E isso só ocorre quando se tem o monopólio legal da violência que permite tomar medidas (ditas essências) de repressão sobre qualquer ameaça à fluidez econômica neoliberal. Um Estado que articula administração das pessoas por meio da violência física e moral. Por isso, como já afirmamos, muitas vezes, a violência contra as populações tradicionais tem partido de quem deveria protegê-las: o Estado. Nesse sentido, a condição de Estado de exceção em que vivem minorias étnicas e raciais torna-se alarmante. O próprio Estado tornou-se difusor do terrorismo pelas ações de repressão, violência, despejos, morosidade e negligência nos processos de regularização fundiária das terras indígenas e quilombolas no Brasil.

Considerando essa nova configuração constitucional do país, isto é, o Estado de exceção com a desfigurada política contemporânea, os dados de 2017 da Comissão Pastoral da Terra (CPT) revelaram que, de modo geral, o ano de 2017 deu um salto agudo de violência no campo. Foram de 71 assassinados no campo em função de lutas envolvendo a questão agrária. Essa nova configuração constitucional, segundo Porto-Gonçalves (2018, p. 2), agride todos os direitos das populações tradicionais. Por um lado, a "facilidade de investimento de terras para estrangeiros, por exemplo, inclusive com presença cada vez maior de grandes agentes de fundos de pensão", que transformaram a terra em um ativo financeiro. "Então é a terra como ativo financeiro e a facilidade que o governo está dando para atrair esses investimentos (...) você tem capital disponível em mercado financeiro internacional e terras que no Brasil a gente sabe como são tituladas". Essa configuração imprime um movimento arrasador de desterritorialização/precarização dos povos indígenas, a exemplo dos Guarani e Kaiowá, pelo avanço territorial do próprio capitalismo com seus investimentos de capital estrangeiro.

Conforme os dados da Comissão Pastoral da Terra (CPT), na Região Centro-Oeste, o número de famílias sob a ameaça de pistoleiros quase triplicou entre 2016 e 2017, passando de 843 para 2.393, e as famílias ameaçadas de expulsão foram de 862 para 2.690. Nesta região, o estado do Mato Grosso do Sul concentrou os conflitos envolvendo indígenas. Nos conflitos por terra, 
as ocorrências de 2016 e 2017 são as mais elevadas desde quando a CPT começou a fazer este trabalho em 1985. Em 2016 foram 1.079 ocorrências e, em 2017, 989. Números nunca atingidos nos 30 anos anteriores. Somando as 771 ocorrências de 2015, tem-se uma média anual no período da ruptura política (2015-2017) de 946 ocorrências, ou seja, 36,1\% maior que a média dos 10 anos imediatamente anteriores (2005-2014).

A partir destes dados é possível afirmar que o desrespeito aos direitos das populações tradicionais faz parte de uma política de insegurança socioterritorial adotada pelo Estado brasileiro. A tanatopolítica ${ }^{5}$ (ESPOSITO, 2006), o "racismo de Estado" (FOUCAULT, 1999), e a necropolítica MBEMBE (2011) estão no cerne destas violações de direitos aos territórios originários. Lembrando que consideramos, conforme Mondardo (2013; 2018a), que o território é um direito que condensa outras formas de defesa e conquista de direitos, tais como educação, saúde, alimentação, segurança, dentre outros. Essa situação de desrespeito aos direitos dos povos indígenas demonstra uma condição de vivência destas populações tradicionais em Estado de exceção permanente. O direito a viver está condicionado à subdivisão da população, pelo "racismo de Estado", em segmentos diferenciados pelo chamado "nível de civilização". Algumas vidas passam a ser consideradas "indignas de serem vividas" (AGAMBEN, 2004, p.146), num jogo ambivalente que permite, dependendo da relação de forças, o fazer viver ou o fazer morrer, por exemplo, de determinados grupos étnicos.

O Estado pode investir e fazer viver certos segmentos da população indígena quando lhe interessar, ou fazer morrer quando estas vidas não estiverem na esteira dos interesses da Nação. Não podemos esquecer que os direitos conquistados pelas minorias étnico-raciais estão relacionados à capacidade de organização e mobilização na forma de movimentos de luta, resistência, contra/com o Estado e ao modo de produção capitalista (SOUZA, 2017). A omissão do poder público, a morosidade nos processos de regularização fundiária (a diminuição acentuada do ritmo das demarcações de Terras Indígenas no Brasil desde a última década), a "contenção territorial" (HAESBART, 2014) de populações relativamente numerosas em pequenas reservas apinhadas de índios e a situação de precariedade, estão entre as violações mais praticadas contra as populações tradicionais.

De acordo com a FUNAI (2016), no Brasil existiam 462 terras regularizadas, que correspondem a $12,2 \%$ do território nacional. Por região, as Terras Indígenas regularizadas estão distribuídas da seguinte maneira: $54 \%$ estão no Norte; $19 \%$ no Centro-Oeste; $11 \%$ no Nordeste; $10 \%$ no Sul; $6 \%$ no Sudeste. A maior parte delas está concentrada na Amazônia Legal e esse fato é explicado pela política de integração nacional e consolidação das fronteiras norte e noroeste na década de 1980. Nas demais regiões do país, os povos indígenas foram mantidos em áreas redu-

\footnotetext{
${ }^{5}$ Esposito (2006), ao analisar o fenómeno do nazismo, desenvolve o paroxismo do "paradigma imunitário", no momento em que a biopolítica foucaultiana se converte, em função desse mesmo paradigma, em uma tanatopolítica, ou política da morte. O nazismo aparece, nessa visão, como o momento em que um poder biopolítico, enquanto poder terapêutico junto de uma população considerada como vida exposta à ação pretensamente imunizante e protetora do poder, e se traduz num poder que despoja a vida de qualquer proteção, num poder que a torna simples "vida nua", no sentido que foi atribuído por Giorgio Agamben, e que se assume diante dela, nessa medida, como uma pura e simples possibilidade de matar. Em face do poder biopolítico sobre a vida, a política de morte ou tanatopolítica tende a culminar um poder soberano imunitário que se afirma enquanto tal como um poder de dominar, dirigir, manipular e mesmo matar a vida. Nesse sentido, por meio da biopolítica contemporânea podemos pensar novos e mais alargados sentidos para a vida de grupos étnicos no Brasil.
} 
zidas e esparsas, muitas delas reconhecidas pelo Serviço de Proteção ao Índio (SPI) entre os anos de 1910 e 1967, sem levar em conta os requisitos necessários para reprodução biológica, cultural e territorial dos povos indígenas. De acordo com os dados da FUNAI de 2016, no estado de Mato Grosso do Sul 29 terras indígenas estão regularizadas, 5 homologadas, 10 declaradas, 4 delimitadas e 15 em estudo. Essa situação territorial permite afirmar que os grupos étnicos deste estado residem em 29 Terras Indígenas, enquanto 34 Terras estão em fases de processos de regularização fundiária.

No "campo verde" sul-mato-grossense as fazendas do agronegócio apresentam a territorialização hegemônica da soja, milho, cana-de-açúcar e pecuária e, contraditoriamente, com pouca vida humana. Se considerarmos, por exemplo, uma proporção entre a população do Mato Grosso do Sul composta por 2.713,147 habitantes em 2017, segundo o IBGE, com o rebanho bovino do estado formado por 21.824,000 milhões de cabeça de gado, segundo levantamento da IAGRO, teremos um percentual de aproximadamente oito bois para cada pessoa. Nessa banalização da vida, ou "boipolítica", "um boi vale mais do que a vida de um indígena Guarani e Kaiowá". Como afirmou um Kaiowá que habita acampamento de área de retomada, "falaram que vai cair a exportação da soja, de milho e de carne do Mato Grosso do Sul. Mas não vai cair nada. A gente só quer um pedacinho de terra que foi tomada" (Tekoha Guyra Kambi'y, município Douradina/MS, entrevista realizada em 27/06/2018). Sob uma crença no Deus-mercado, é melhor exportar soja, milho e carne do que regularizar as terras indígenas por ordenamento territorial construído pelo e para os debaixo, e que permita a esses povos viver na e com a floresta. Nessa perspectiva onipotenteonipresente mercadológica, o indígena é coisificado, desconsiderando, assim, a sua territorialização histórica com a terra e de resistência nos territórios.

Agamben (2004) reconhece nas mudanças da sociedade contemporânea um regime de "Estado de exceção" erigido por leis de excepcionalidade que, ligadas ao poder soberano, tornamse, hoje, a regra, pois, "inicialmente apresentadas como medidas ligadas a acontecimentos excepcionais, reservadas a situações limitadas no tempo e no espaço, tornam-se regra" (p. 76). Para o autor, o Estado de exceção não deve ser mais visto como um regime adotado em uma situação circunstancial e/ou extraordinária, principalmente, empregada em um momento de emergência. Esse regime deve ser compreendido, hoje, como uma "técnica de governo" que funciona para a "administração da vida" e, consequentemente, da própria morte, por meio da tanatopolítica. Assim como a vida, a morte é uma questão política. Foucault (2004) tratou da biopolítica, o cálculo que o poder faz sobre a vida, junto da tanatopolítica, cálculo do poder sobre a morte.

Como contraponto ao racismo de Estado (FOUCAULT, 1999) implantado pela lógica biopolítica/necropolítica colonial (MBEMBE, 2011), uma das formas de descolonização do imaginário geográfico hegemônico se deve às estratégias decoloniais políticas, práticas e discursos (a práxis), colocados em curso que reconstruíram novas territorialidades dos povos indígenas em luta diante do esforço coletivo de um grupo social para reocupar, usar, controlar, identificar e reapropriar uma parcela espaço. Converte-se, assim, por meio das práticas territoriais de resistência, em seu território (conforme acepção de Sack, 1983). Nessa disputa, se por um lado fazendeiros (muitos destes, "gaúchos"6) buscam sua legitimidade pela manutenção da propriedade da terra (a

\footnotetext{
${ }^{6}$ No Mato Grosso do Sul, a fronteira do Brasil com o Paraguai atraiu paranaenses, catarinenses e gaúchos (conhecidos genericamente como "gaúchos"), que migraram em busca de terras, de trabalho, de riquezas e de um território para a reprodução de suas relações sociais. Os fazendeiros "gaúchos" analisados nesta pesquisa são aqueles que personifi-
} 
chamada "segurança jurídica"), de outro, os Guarani e Kaiowá lutam pelo direito constitucional por meio do reconhecimento de seus territórios tradicionalmente ocupados em busca de justiça social. Nesse conflito, temos disputas de concepções e práticas de territórios, de um lado, pelas fazendas do agronegócio, e do outro, pelas ações coletivas diretas de retomadas de territórios tradicionais.

\section{Retomadas de territórios tradicionais}

Nas últimas décadas, no campo brasileiro, vem ganhando força as ações coletivas diretas de luta pela terra, estrategicamente denominadas de retomadas de territórios tradicionais e/ou autodemarcação. Essas ações coletivas ganham variações semânticas e formas de territorialização alternativa, a depender da terra, dos territórios requeridos e da cosmografia ${ }^{7}$ dos grupos sociais envolvidos, tais como: retomadas territoriais, retomadas de tekoha, retomadas de territórios originários, retomadas da terra sagrada, retomadas de quilombos, retomadas de povos e comunidades tradicionais, reocupação, recuperação, autodemarcação, dentre outras. O sentido prático, político, normativo, simbólico-sagrado atribuído e aplicado nas retomadas torna o território um conceito catalizador de direitos, de rituais, e de mobilização, organização, reelaboração e reinvenção das territorialidades de resistência nos movimentos das populações tradicionais. A luta é pela "reapropriação social da natureza" (LEFF, 2006) frente à geopolítica da despossessão, as novas dependências e a reprimarização da economia em curso promovida no Brasil pela territorialização do agronegócio, do neoextrativismo, de hidrelétricas, dentre outras.

A área de retomada normalmente é aquela em que estão situados os conflitos e confrontos. Existem retomadas em condições territoriais, políticas e jurídicas muito distintas, assumindo variações pela forma de territorialização e dos sujeitos coletivos, étnico-raciais - as chamadas comunidades "remanescentes" em termos de emergência étnica e reinvenção cultural, como sugere Arruti (1997) -, envolvidos na luta pela terra e dos grupos hegemônicos contrários aos movimentos de retorno aos territórios tradicionais.

No contexto de negação dos direitos territoriais, os Guarani e Kaiowá, inconformados com a imposição do Estado de "contenção territorial" (HAESBAERT, 2014), e de territorialidades compulsórias nas reservas - "espaços mínimos" de controle e disciplina -, transformaram as ações diretas de retomadas de territórios tradicionais, a autodemarcação de tekoha, em estratégias biopolíticas de vida em resistência. Um Kaiowá que mora em um acampamento às margens de rodovia, considera a retomada uma ação autônoma do seu grupo étnico:

\footnotetext{
cam de maneira mais radical esta "condição moderna" do agronegócio, latifundiários em sua maioria, e que assumem posições radicalmente contrárias aos processos de demarcação das terras indígenas (MONDARDO, 2009a; 2009b; 2012; 2018a). É importante lembrar que essa dinâmica envolve o processo de mobilidade de "gaúchos" e do capital que deslocaram cooperativas agrícolas dos estados do Sul do Brasil (Paraná, Santa Catarina e Rio Grande do Sul) e, a partir da década de 1970, impulsionados pelo Estado e pela grande "oferta" de terras, "invadem" o interior do Brasil para a expansão da fronteira agrícola (HAESBAERT, 1995; 1997). Para um aprofundamento dos conflitos territoriais entre fazendeiros "gaúchos" e povos Guarani e Kaiowá, ver Mondardo (2018a).

7 Com base na Antropologia territorial, Little (2002, p. 254) considera a cosmografia uma importante acepção para entender a relação particular que um grupo social mantém com seu território. O autor define cosmografia "como os saberes ambientais, ideologias e identidades - coletivamente criados e historicamente situados - que um grupo social utiliza para estabelecer e manter seu território. A cosmografía de um grupo inclui seu regime de propriedade, os vínculos afetivos que mantém com seu território específico, a história da sua ocupação guardada na memória coletiva, o uso social que dá ao território e as formas de defesa dele".
} 
Uma ação autônoma. A retomada é uma área. A gente bebe água na nascente. $A$ gente não comia carne, não tem caça. Onde a gente vive não tem energia. Até hoje eu durmo na rede. Morar na retomada um pouco é bom, um pouco a gente se sente ameaçado. A gente mora na retomada. (...) viver na retomada é resistência. Desde os cinco anos eu moro na área de retomada, eu sei o que é viver a resistência. Na reserva não é o lugar de nós morar. Não é a nossa vida de viver. A reserva foi criada pelo Estado. O tekoha é o lugar de viver. Lá é que tem a resistência para a gente viver. (...) Retomada é para requerer nosso tekoha. A retomada é um recomeço para nós. É um recomeço para nós requerer a nossa terra, um novo começo para nós. (Kaiowá do Tekoha Guyra Kambi'y, município de Douradina/MS, entrevista realizada em 27/06/2018).

No debate sobre território e colonialidade do saber e do poder, as retomadas são ações autônomas na luta pelos direitos à terra, educação, saúde, alimentação, segurança, dentre outras necessidades e demandas. Desse processo de tensão e conflito entre fazendeiros e indígenas, produziram-se novas e alter-nativas territorialidades de resistência na luta contra o preconceito, exploração, ocultamento e invisibilidade, para a valorização e afirmação simbólico-cultural da identidade territorial dos Guarani e Kaiowá. No município de Dourados, onde residem aproximadamente $20 \%$ da população indígena do estado sul-mato-grossense, esses povos organizam-se em ações coletivas de enfrentamento direto, seja pelo fechamento temporário de rodovias, ocupações de áreas com estudos de demarcações e/ou praticam-se trânsitos multi e até transterritoriais pela fronteira internacional entre acampamentos e reservas, com o objetivo de fortalecer a luta e retroalimentar a resistência do grupo para o retorno aos tekoha (MONDARDO, 2018b).

Como contrapondo as fazendas e reservas etnocidas com a lógica de atuação do Estado pela biopolítica colonial de integração dos indígenas via assimilação cultural e desterritorialização dos seus tekoha pela acumulação por despossessão, os Guarani e Kaiowá reelaboram o tekoha na contemporaneidade por meio de uma visão de território comunal e de usufruto coletivo da terra, que tem por base a família extensa em uma área identificada e estratégica para a vivência, garantia de reprodução e continuidade, ou seja, a preocupação com o futuro do grupo étnico manifestada em sua territorialidade. A vida nos tekoha antigos era compartilhada num sistema comunitário que buscava potencializar a participação das famílias em sua organização espacial. Enquanto categoria de análise e da prática (geográfica e nativa) para os povos Guarani e Kaiowá, o tekoha tornou-se tekohahã - em devir - um espaço de r-existência. É concomitantemente tanto um território geográfico como epistêmico, de memória das lutas em que a morte se tornou, hoje, mais um elemento de fortalecimento que retroalimenta a organização, mobilização e as ações coletivas diretas das lutas. Como sentencia Valdelice Veron (2011), liderança Guarani e Kaiowá, "seguimos com luto e san-gue demarcando as terras indígenas".

Para Morais (2017), a relação dos Kaiowá com a morte e a terra em meio à violência extrema no Mato Grosso do Sul reelabora as territorialidades. No drama vivido pelos Guarani e Kaiowá "a morte e o morto assumem um lugar produtivo na composição dos coletivos atuais que vivem nas 'retomadas', adensando a história locais, as relações parentais e a legitimidade da luta pelo território" (MORAIS, 2017, p. 40). Por isso, a dor da perda de um parente se mistura com a celebração da força do coletivo, e alimenta o sentimento de irredutibilidade do desejo de viver com os parentes mortos no tekoha. O tema do morto e da morte, por isso, tem uma conectividade com o direito a terra e o território.

Renitentes com a imposição da contenção/disciplina nas reservas, as retomadas de territórios tradicionais transpassam seus limites, podendo ser pensadas como espaço da resistência dos 
corpos dos vivos, mesmo ao custo do risco efetivo de sua transformação em corpo morto pelas violências e precariedades sofridas. Por sua vez, os corpos mortos nas retomadas desenvolvem uma relação especial e profundamente significativa com os parentes vivos, que permanecem no território reconquistado, legitimado pela morte e pelo enterro das vítimas de violência. $\mathrm{O}$ ano de 2016, por exemplo, ficou marcado como "O Massacre de Caarapó", o confronto entre indígenas e fazendeiros por conta dos primeiros ocuparem a Fazenda Yvu, próxima à reserva Tey Kuê, com 4.930 habitantes, no município de Caarapó, que faz parte da área com estudo para a demarcação Dourados Amambaipeguá I, mais especificamente, no Tekoha Toropaso. O dia 12 de junho de 2016 marcou o início do confronto com cerca de 300 indígenas da etnia Guarani e Kaiowá, acampados na área de retomada, e lutando para reconquistar seu espaço, um tekoha antigo com aproximadamente 56 mil hectares, que faz parte hoje de uma fazenda com 490 mil hectares. No entanto, essa luta recebeu o ataque de fazendeiros, jagunços e pistoleiros que, juntos, utilizaram retroescavadeiras, atearam fogo nos pertences dos Guarani e Kaiowá e fizeram uso de armas de fogo. Desse confronto resultou em oito feridos e o assassinato do agente de saúde Clodiodi Aquileu Rodrigues de Souza.

Essa luta territorial se intensificou quando o corpo do indígena foi enterrado no local da disputa e a área mudou de nome, passando de Tekoha Toropaso para Tekoha Kunumi Poty Verá, nome indígena de Clodiodi. Essa ressignificação territorial demonstra um movimento de fortalecimento pela carga simbólica que a resistência ganha quando a morte se torna um fator produtivo de mobilização e organização do grupo étnico. Aqui ficam evidentes os fatores de proteção destes povos, como os rituais e a religiosidade. Isso ocorre justamente pela cosmologia indígena, ou seja, a forma como foi construído o modo de viver e como o mesmo se transforma na relação entre o indígena morto e seu grupo étnico em áreas de agronegócio marcadas por desreterritorializações, lutas, conflitos e confrontos. É possível afirmar, nesse caso, que a morte tornou-se mais um elemento de luta, organização, mobilização e reelaboração cultural das territorialidades para as ações de retomada dos territórios tradicionais.

Outro exemplo da reelaboração das territorialidades na relação com os assassinatos indígenas pode ser identificado no acampamento de retomada Apyka'i. Localizado a sete km do centro da cidade de Dourados, às margens da BR 463, trecho que liga Dourados à Ponta Porã, e tem como sua líder, a mais de uma década, Dona Damiana, que é cotidianamente ameaçada por mandados de reintegração de posse, isto é, despejos. "Dona Damiana, da área de retomada Apika'y, vive a mais de 12 anos na beira da estrada" como nos informou seu parente Kaiowá. A área do acampamento às margens da rodovia onde vive demonstra que o tekoha está cercado pela cana e soja. No acampamento ocorreram constantes mortes dos parentes da cacique, sendo que no período de 1999 e 2014, ao menos sete foram atropelados na rodovia pela violência etnocida de fazendeiros contra os Kaiowá acampados.

Os conflitos e mortes nas reservas e acampamentos de retomada têm a ver com os corpos e as almas destes povos, que por sua vez compõem e decompõem na terra e com o território, indissociáveis, portanto da proliferação de novos acampamentos, de novas retomadas, das mobilizações políticas, das relações de parentesco, dos rituais, da reelaboração das territorialidades. Esses corpos e almas dos Guarani e Kaiowá assassinados estão implicados hoje no próprio conceito de tekoha, assim como na busca da terra "sem males", do bem viver, e emprega sentido futuro às territorialidades indígenas que resistem à violência, à morte, à resignação, ao fim do 
mundo. No conflito com os fazendeiros, os territórios Kaiowá são produzidos pelo coração e pela memória de luta que inclui os parentes/lideranças assassinadas, que apresentam formas e conteúdos geográficos que se desterritorializam e desterritorializam, e assim incorporam a contingência da experiência, em devir, o sonho de vir a ser tekohahã. Nesse drama humanitário, conforme as percepções propriamente dos Kaiowá, o tekoha é um direito aos corpos dos indígenas vivos e dos mortos.

Nessa dinâmica espaçotemporal que reinventa territorialidades, o tekoha se tornou uma ação coletiva de uma parcela de Guarani e Kaiowá que se mobilizam para afirmação de seu discurso de valorização étnica e de práticas de retomadas territorializadas pela tradicionalidade de ocupação do espaço. ${ }^{8} \mathrm{Na}$ fronteira do Brasil com o Paraguai existem áreas de retomadas de indígenas que residem no Mato Grosso Sul, em terras lindeiras ao limite internacional. Pode-se apontar o caso de indígenas Guarani Ñhandeva da reserva Pirajuí, no sul do estado, que praticam retomadas territoriais em áreas fronteiriças com o Paraguai. Nesse caso, identificamos retomadas de territórios tradicionais que podem ser chamadas de transterritoriais (HAESBAERT; MONDARDO, 2010) na forma geográfica em que elas transgridem, "rompem" ou relativizam os limites do território nacional, projetando-se sobre o país vizinho. Esse movimento de autodemarcação redesenha os limites das fazendas do agronegócio pelas ações coletivas de retomadas, étnico-territoriais, nessa zona de fronteira.

Os povos Guarani e Kaiowá produzem um movimento (trans)fronteiriço de resistência de longa data, sobretudo entre as gerações mais antigas que tinham na mobilidade (itinerante) um componente central de suas territorialidades, nesse trânsito entre Brasil e Paraguai, entre os estados brasileiros de Mato Grosso do Sul e Paraná, com os departamentos paraguaios de Amambay, Concepción, Alto Paraná e Canindeyú. Hoje, pela dimensão de luta por território e direitos humanos que o movimento indígena ganhou, essas territorialidades foram reconfiguradas em resistência em torno de um objetivo comum: a demarcação das terras tradicionalmente ocupadas em áreas lindeiras aos limites internacionais.

Por isso, podemos considerar que essa mobilidade se caracteriza como uma territorialidade de trânsito na medida em que essas retomadas de tekoha se manifestam como a possibilidade concreta e simbólica, o devir indígena, de "ter uma terra nova para nós usar" (yuy pyahu), como nos disse uma jovem Guarani Ñandeva (entrevista realizada em 25/05/2018). Essa necessidade de mudar de área (Ojequerova) caracteriza-se não como um trânsito efêmero, mas concreto e efetivo, nesta zona de fronteira, compondo movimentos de desreterritorialização de reservas indígenas, como no caso de Pirajuí, no Brasil, em direção às áreas de retomadas do lado paraguaio, fronteiriças aos limites internacionais, de uso e ocupação originária, das comunidades tradicionais Guarani Ñandeva que se territorializavam historicamente no tekoha quasu.

\footnotetext{
${ }^{8}$ A socióloga argentina Svampa (2019, p. 38) afirma que no início deste século XXI para os povos indígenas da América Latina uma das dimensões constitutivas da resistência social contra as novas estruturas de dependência comercial como fornecedor de commodities agrícolas e minerais, caracterizado pelo neoextrativismo e reprimarização da economia, é a defesa do território e da territorialidade. "Certamente, território e territorialidade são conceitos disputados, pois não aparece apenas na narrativa de organizações indígenas e movimentos socioambientais, mas também no discurso de corporações, planejadores, projetistas de políticas públicas, enfim, poder político, em suas diferentes escalas e níveis. Em suma, a noção de território tornou-se uma espécie de conceito social total, a partir do qual é possível visualizar o posicionamento dos diferentes atores em conflito e, mais ainda, a partir dele analisar as dinâmicas sociais e políticas."
} 


\section{Considerações finais}

No estado do Mato Grosso do Sul, em relação aos direitos territoriais e humanos dos povos indígenas Guarani e Kaiowá, a negação cotidiana e sistemática configura um Estado de exceção. Para estes povos parece não haver "direito a nada". O Estado violenta sistematicamente os direitos coletivos, a exemplo da terra e do território (tekoha), e os direitos humanos.

Desde a criação de reservas indígenas, passando pelas frentes de ocupação e colonização até a modernização da agricultura e a implantação do agronegócio, identifica-se a questão do domínio e do controle da terra pelo não indígena na fronteira do Brasil com o Paraguai. Entre os anos de 1915 a 1928, o Serviço de Proteção aos Índios criou oito pequenas áreas - reservas indígenas multiétnicas - que desterritorializou/expulsou os povos indígenas por meio da espoliação de seus tekoha. A criação das reservas pela biopolítica colonial do Estado brasileiro foi um fenômeno basilar para a negação dos direitos territoriais indígenas e a tentativa de integração à sociedade nacional pela lógica de desterritorialização (destruição de seu teko-ha, o modo de vida e organização socioespacial) por meio da assimilação cultural. O dispositivo do território-zonareserva foi utilizado pelo Estado para impor uma lógica de sujeição às territorialidades indígenas pela definição de novos limites socioterritoriais com a criação de "espaços mínimos" de sobrevivência. Nesse processo de expansão da sociedade nacional pelas frentes de colonização as terras indígenas foram saqueadas pelo Estado e liberadas para as frentes de colonização implantar suas lógicas de acumulação por espoliação.

A condição de Estado de exceção em que vivem estas populações torna-se alarmante, pois o próprio Estado tornou-se difusor do terrorismo pelas ações de violência física e simbólica, despejos, ameaças, intimidações e assassinatos. Não faltam ocorrências de conflitos e confrontos entre o poder público, de polícia (municipal, estadual e federal), articuladas por vezes com o poder privado, fazendeiros, multinacionais e até empresas particulares de "segurança", com ordens de despejo e/ou expulsões dos povos indígenas de áreas de retomadas, bem como de seus territórios originários. A vigilância territorial no Mato Grosso do Sul é integrada por sindicatos patronais, militares da reserva e da ativa, comerciantes, fazendeiros e empresas multinacionais, que vem profissionalizando a violência e terceirizando a gestão dos conflitos fundiários no estado. Com isso se configura um Estado de exceção permanente pela realidade de negação cotidiana de direitos consuetudinário-constitucionais dos povos indígenas. O resultado desse racismo de Estado é a lógica necropolítica instaurada, nas violências sofridas como demonstrado nesta pesquisa pelos alarmantes índices de assassinatos contra os Guarani e Kaiowá nesse pedaço do Brasil profundo.

Os conflitos e mortes nas reservas e acampamentos de retomada são indissociáveis, hoje, da proliferação de novos acampamentos, de novas áreas de retomadas, das mobilizações políticas, das relações de parentesco, dos rituais. Esses corpos e almas dos Guarani e Kaiowá assassinados estão implicados no próprio conceito de tekoha, assim como na busca da terra "sem males", do bem viver e emprega sentido futuro às territorialidades indígenas que resistem à violência, à morte, à resignação, ao fim do mundo. No enfrentamento com os fazendeiros, os territórios Guarani e Kaiowá são produzidos pela memória dos conflitos, dos parentes/lideranças assassinadas. Nesse drama humanitário, conforme as percepções propriamente dos Kaiowá, o tekoha é um direito aos corpos dos indígenas vivos e dos mortos. A dor da perda de um parente se mistura com 
a celebração da força do coletivo, e alimenta o sentimento de irredutibilidade do desejo de viver com os parentes mortos no tekoha. O tema do morto e da morte tem uma conectividade com o direito a terra, o território e reelabora as territorialidades.

Os Guarani e Kaiowá estão presos em seu próprio território, que hoje é controlado pelas modernas fazendas, articuladas com as empresas multinacionais e o Estado. Esses povos originários estão pelejando para viver e sobreviver em ações coletivas como as de retomadas de tekoha. Se, de um lado, as empresas exploram os territórios e abusam dos recursos naturais como a terra e a água, contaminando-os com práticas inadequadas de exploração econômicas, do outro lado, uma parcela de Guarani e Kaiowá, num movimento de resistência antissistêmico, fazem a autodemarcação em ações coletivas estratégicas e diretas de retomadas territoriais em ambos os lados da fronteira entre Brasil e Paraguai.

Nesse contexto conflituoso de regularização fundiária, são necessárias políticas públicas sérias e comprometidas com o combate à violência para a segurança dos povos indígenas nas reservas, em áreas de retomada e em seus tekoha, e para que se garantam os direitos constitucionais da territorialização tradicional. É dever do Estado garantir a demarcação das terras indígenas e consequentemente viabilizar o acesso à educação, saúde, alimentação, contextualizada nos territórios de ocupação originária. A morte, nesse espaço de conflitos e confrontos, foi ressignificada pela memória das lutas dos guerreiros assassinados ao se tornar mais um componente simbólico de fortalecimento para se retomar, reocupar e viver no tekoha.

Como foi afirmado na VI Kuñangue Aty Guasu (Grande Assembléia das Mulheres Kaiowá e Guarani) junto com a Aty Guasu e a RAJ (Retomada Aty Jovem), realizada entre os dias 10 e 14 de julho de 2018, na Reserva Índígena de Amambai, em Mato Grosso do Sul, "vivemos a insegurança pública no nosso cotidiano, tendo que lidar com o racismo, o preconceito, a violação de nossos corpos e de nossa cultura, com as violências dos não indígenas quando tentamos utilizar os dispositivos do Estado que oficialmente deveriam nos proteger enquanto mulheres. (...) Sem a demarcação das nossas terras, nós mulheres Guarani e Kaiowá não poderemos ter uma vida livre da violência. para que possamos ter uma vida com liberdade junto com nossos filhos, nosso povo, em nossa terra". Esse protagonismo de mulheres indígenas em luta pela demarcação de suas terras frente à negação de seus direitos abre horizontes com o empoderamento e a organização de novas territorialidades " para que possam seguir juntos com esses territórios. que sonham, que sentem e que choram, tem vida, pelejam e sentem dor”, como afirmou uma liderança feminina Guarani e Kaiowá em acampamento de retomada. 
Referências

AGAMBEN G. Estado de exceção. São Paulo: Boitempo, 2004.

AGAMBEN G. Homo Sacer: o poder soberano e a vida nua I. Belo Horizonte: EdUFMG, 2002.

ARRUTI, J. M. A. A emergência dos "remanescentes": notas para o diálogo entre indígenas e quilombolas. Mana. vol.3, n.2, 1997, p.7-38.

BRASIL. Constituição da República Federativa do Brasil. Brasília, DF: Senado Federal: Centro Gráfico, 1988. 292p.

COMISSÃO PASTORAL DA TERRA - CPT. Conflitos no campo - Brasil 2017. Goiânia: CPT Nacional $\quad-\quad$ Brasil, $2017 . \quad$ Disponível em: https://www.cptnacional.org.br/component/jdownloads/send/41-conflitos-no-campo-brasilpublicacao/14110-conflitos-no-campo-brasil-2017-web?Itemid=0 - Acesso em: 29/10/2018.

CONSELHO INDIGENISTA MISSIONÁRIO - CIMI. Violência contra os Povos Indígenas no Brasil - Dados de 2012. Brasília: CIMI, 2013.

Violência contra os Povos Indígenas no Brasil - Dados de 2014. Brasília: CIMI, 2014. . Violência contra os Povos Indígenas no Brasil - Dados de 2016. Brasília: CIMI, 2016.

CRESSWELL, T. Geographic thought: a critical introduction. Malden, MA: Wiley Blackwell, 2013.

DELEUZE, G. O anti-édipo: capitalismo e esquizofrenia 1. Lisboa: Assírio \& Alvim, 2004.

DUPRAT, D. "Dourados é talvez a maior tragédia conhecida na questão indígena em todo o mundo". Conselho Indigenista Missionário - CIMI. As violências contra os povos indígenas em Mato Grosso do Sul: e as resistências do bem viver por uma terra sem males (dados 2003-2010). Mato Grosso do Sul: CIMI, 2011, p. 24-27.

ESPOSITO, R. Bíos: Biopolítica y filosofia. Buenos Aires/Madrid: Amorrorttu editores, 2006.

FLICK, U. Combining methods: lack of methodology. Ongoing Productions on Social Representation, 1(1), 43-48, 1992.

FOUCAULT, M. Em defesa da sociedade: curso do Collège de France (1975-1976). São Paulo: Martins Fontes, 1999.

Naissance de la Biopolitique. Paris: Gallimard-Seuil, 2004.

FRASER, N. A justiça social na globalização: redistribuição, reconhecimento e participação. Revista Crítica de Ciências Sociais, 63: 7-20, 2002. FRASER, N. Redistribución ou reconocimiento? In: FRASER, N. \& HONNETH, A. Redistribución ou Reconocimiento? Madrid: Ediciones Morata, 2006.

. La justicia social en la era de la política de la identidad: Redistribución, reconocimiento y participación. In: FRASER, N. \& HONNETH, A. Redistribución ou Reconocimiento? Madrid: Ediciones Morata, 2006, p. 17-88.

FUNAI. Fundação Nacional do Índio. Povos e terras indígenas. 2016. Disponível em http://www.funai.gov.br/index.php/indios-no-brasil/quem-sao - Acesso em: 12/05/2017. 
FUNAI. Terras indígenas, o que é?. Disponível em: http://www.funai.gov.br/index.php/2014-0207-13-24-32?limitstart=0\# consultado em 05/11/2016.

. Terras indígenas. Disponível em: http://www.funai.gov.br/index.php/indios-nobrasil/terras-indigenas consultado em 05/11/2016.

HAESBAERT R. "Gaúchos” no Nordeste: modernidade, des-territorialização e identidade. Tese de Doutorado em Geografia. São Paulo: FFLCH-USP, 1995.

. Des-territorialização e identidade: a rede "gaúcha" no Nordeste. Niterói: EDUFF, 1997.

Armadilhas do território. In: BORZACCHIELLO DA SILVA, J.; SILVA, C. N. M. da.; DANTAS, E. W. C. (Orgs). Território: modo de pensar e usar. Fortaleza: Edições UFC, 2016, p. 19-42.

. Le mythe de la déterritorialisation. Géographies et Cultures. n. 40. Paris: L'Harmattan, 2001.

Viver no limite: território e multi/transterritorialidade em tempos de in-segurança e contenção. Rio de Janeiro: Bertrand Brasil, 2014.

HAESBAERT, R.; MONDARDO, M. Transterritorialidade e antropofagia: territorialidades de trânsito numa perspectiva brasileiro-latino-americana. GEOgraphia, n. 24, 2010.

HARVEY, D. A loucura da razão econômica: Marx e o capital no século XXI. São Paulo: Boitempo, 2018.

. O novo imperialismo. São Paulo: Loyola, 2004.

IAGRO. Agência Estadual de Defesa Sanitária Animal e Vegetal. Rebanho bovino de Mato Grosso do Sul. Disponível em: http://www.iagro.ms.gov.br/ - acesso em 11/02/2018.

IBGE. Etnias indígenas mais numerosas por Unidades da Federação - 2010. Disponível em: $<$ https://www.ibge.gov.br/apps/atlas_nacional/pdf/14\%20-

\%20ETNIAS\%20INDIGENAS\%20MAIS\%20NUMEROSAS\%20POR\%20UNIDADES\%20DA \%20FEDERACAO\%20-\%202010.pdf> - acesso em 06/10/2017.

LEFF, E. Racionalidade ambiental: a reapropriação social da natureza. Rio de Janeiro: Civilização Brasileira, 2006.

LITTLE, P. Territórios sociais e povos tradicionais no Brasil: por uma antropologia da territorialidade. Série Antropologia n. 322. Brasília, UnB: 2002.

LOREY, I. State of Insecurity: government of the precarious. London: Verso Books, 2015.

MBEMBE, A. Necropolítica. Melusina, Tenerife, 2011.

MIGNOLO, Walter. Histórias locais/projetos globais: colonialidade, saberes subalternos e pensamento liminar. Belo Horizonte: UFMG, 2003.

MONDARDO M. Os períodos das migrações: territórios e identidades em Francisco Beltrão/PR. Dissertação (Mestrado em Geografia), Faculdade de Ciências Humanas, Universidade Federal da Grande Dourados. Dourados/MS, 2009a. 
MONDARDO, M. A dinâmica multi/transterritorial dos povos Guarani e Kaiowá na fronteira do Brasil com o Paraguai. In: RÜCKERT, A. A.; SILVA, A. C. P. da; SILVA, G. de V. (Orgs.). Geografia Política, Geopolítica e Gestão do Território: integração sul-americana e regiões periféricas. Porto Alegre: Editora Letra1, 2018a, p. 218-233 DOI 10.21507/9788563800367-13

A geometria de poder do conflito territorial entre fazendeiros e Guarani-Kaiowá na fronteira do Brasil com o Paraguai. Acta Geográfica (UFRR), 2014, p. 185-202.

Conflitos territoriais entre Guarani-Kaiowá, paraguaios e "gaúchos": a produção de novas territorialidades no Mato Grosso do Sul. (Tese de Doutorado em Geografia). Programa de Pós-Graduação em Geografia da Universidade Federal Fluminense: Niterói, 2012.

Insecurity territorialities and biopolitical strategies of the Guarani and Kaiowá indigenous folk on Brazil's forderland strip with Paraguay. L'Espace Politique, 31, 2017-1. Consultado em 27/11/2017. Disponível em http://espacepolitique.revues.org/4212; DOI: 10.4000/espacepolitique.4212. Acesso em: 15/01/2019.

. Mobilidade sulista do capital e da força de trabalho para o Mato Grosso do Sul: modernização agroindustrial, descompassos e contradições sócio-territoriais. Terra Livre, v. 1, p. 173-187, 2009b.

. O direito ao território tradicional Guarani-Kaiowá em Mato Grosso do Sul: in-segurança, biopolítica e Estado de exceção. Boletim Dataluta. São Paulo, UNESP, NERA, 2013.

Territórios de trânsito: dos conflitos entre Guarani e Kaiowá, paraguaios e "gaúchos" à produção de multi/transterritorialidades na fronteira. Rio de Janeiro: Consequência, 2018b.

MORAIS, B. M. Do corpo ao pó: crônicas da territorialidade kaiowá e guarani nas adjacências da morte. 1. ed. São Paulo: Editora Elefante, 2016.

OLIVEIRA, F. de. Política numa era de indeterminação: opacidade e reencantamento. In: RIZEK, C. S. (Orgs.). A era da indeterminação. São Paulo: Boitempo, 2007, p. 15-47.

PORTO-GONÇALVES, C. W. Conflitos no campo mostram nova configuração constitucional do país. Disponível em: https://www.brasildefato.com.br/2018/06/05/conflitos-no-campomostram-nova-configuracao-constitucional-do-pais-afirma-professor/index.html - acesso em 13/06/2018.

QUIJANO, A. Colonialidade do poder, eurocentrismo e América Latina. In: LANDER, E. (Org.). A colonialidade do saber: eurocentrismo e ciências sociais. Perspectivas latino-americanas. Buenos Aires: CLACSO, 2005, p. 107-130.

RAFFESTIN, Claude. Por uma Geografia do Poder. São Paulo: Ática, 1993.

RATZEL, F. O solo, a sociedade e o Estado. Revista do departamento de Geografia, USP, 2, 2011. p. 93-101.

RIBEIRO, M. T. F. MILANI, C. R. S. Compreendendo a complexidade socioespacial contemporânea: o território como categoria de diálogo interdisciplinar. (Orgs.). Salvador: EDUFBA, 2009, p. 21-36.

SACK, R. D. Human territoriality: a theory. Annals of the Association of American Geographers, Vol. 73, No. 1. (Mar., 1983), pp. 55-74. 
SANTOS, B. de S. Renovar a teoria crítica e reinventar a emancipação social. São Paulo: Boitempo, 2007.

SANTOS, M. Técnica, espaço, tempo: globalização e meio técnico-científico- informacional. 3 ed. Hucitec: São Paulo, 1997.

SASSEN, S. Expulsiones: brutalidad y complejidad en la economía global. Buenos Aires: Katz Editores: 2015.

SOUZA, M. L. de. Os conceitos fundamentais da pesquisa sócio-espacial. Rio de Janeiro: Bertrand Brasil, 2013.

Por uma geografia libertária. Rio de Janeiro: Consequência Editora, 2017.

SVAMPA, M. Las fronteras del neoextractivismo en América Latina: conflictos socioambientales, giro ecoterritorial y nuevas dependências. Centro Maria Sibylla Merian de Estudios Latinoamericanos Avanzados en Humanidades y Ciencias Sociales: Guadalajara, 2019.

TOURAINE, A. Um novo paradigma: para compreender o mundo de hoje. Petrópolis: Vozes, 2006.

VERON, V. Por que nos matam?. Conselho Indigenista Missionário - CIMI. As violências contra os povos indígenas em Mato Grosso do Sul: e as resistências do bem viver por uma terra sem males (dados 2003-2010). Mato Grosso do Sul: CIMI, 2011, p. 28-31.

WACQUANT, L. Punir os pobres: a nova gestão da miséria nos Estados Unidos. 1. ed. Tradução de Sérgio Lamarão. Rio de Janeiro: Revan, 2007.

WALLERSTEIN, I. O que significa hoje ser um movimento anti-sistêmico. In: LEHER, R. SETÚBAL, M. (Org.). Pensamento crítico e movimentos sociais. São Paulo: Cortez, 2005, p. 263- 276.

WIEVIORKA, M. Em que mundo viveremos? São Paulo: Perspectiva, 2006. 